\title{
Role of Fetal 1,25-Dihydroxyvitamin D Production in Intrauterine Phosphorus and Calcium Homeostasis
}

\author{
EDDIE S. MOORE, CRAIG B. LANGMAN, MURRAY J. FAVUS, AND FREDERIC L. COE \\ Departments of Pediatrics and Medicine, Michael Reese Hospital and Medical Center and the Pritzker School of \\ Medicine, The University of Chicago, Chicago, Illinois 60616
}

\begin{abstract}
During intrauterine life, fetal mineral accretion depends on active transfer from mother to fetus by the placenta. To evaluate the role of fetal production of $1,25-$ dihydroxyvitamin $D$ in regulation of fetal phosphorus, calcium, and parathyroid homeostasis, studies were performed in ewes and their fetal lambs. Fetal nephrectomy caused a rise in fetal serum phosphorus and a fall in total calcium 5 days after nephrectomy. Fetal blood ionized calcium also fell and serum parathyroid hormone rose. In sham-nephrectomized fetuses, all four measurements were unchanged compared to control values. Simultaneous maternal values of ionized calcium were normal in control and nephrectomized fetuses. Fetal ureteral severance and drainage of urine into the fetal peritoneal cavity produced none of the effects of fetal nephrectomy. Daily intravenous injection of 1,25-dihydroxyvitamin $D$ into fetuses after nephrectomy prevented the rise in serum phosphate, and serum calcium did not fall. The results suggest that fetal 1,25-dihydroxyvitamin $D$ regulates fetal phosphate homeostasis, perhaps by the placenta, which in turn regulates blood-ionized calcium concentration. (Pediatr Res 19: 566$569,1985)$
\end{abstract}

Abbreviations
$1,25(\mathrm{OH})_{2} \mathrm{D}_{3}, 1,25$-dihydroxyvitamin $\mathrm{D}$
iPTH, immunoreactive parathyroid hormone
$\mathrm{Nx}$, nephrectomy

During intrauterine life, fetal mineral accretion depends on active transfer from mother to fetus by the placenta $(1,2)$. In humans, fetal skeletal growth requires placental calcium transport of approximately 140 to $200 \mathrm{mg} / \mathrm{kg}$ fetal body weight per day in late gestation $(3,4)$. During pregnancy, $1,25(\mathrm{OH})_{2} \mathrm{D}_{3}$ synthesis occurs in the maternal kidney $(5,6)$, the placenta $(7-$ 9) and the fetal kidney (10). The relative contribution of $1,25(\mathrm{OH})_{2} \mathrm{D}_{3}$ from each of these sources to regulation of fetal mineral homeostasis is not known. In this study we present evidence that fetal kidney production of $1,25(\mathrm{OH})_{2} \mathrm{D}_{3}$ may be important in regulation of fetal serum phosphorus and calcium concentrations and to fetal parathyroid homeostasis.

Received March 14, 1984: accepted February 12, 1985.

Reprint requests Eddie S. Moore, M.D., Department of Pediatrics, Michael Reese Hospial and Medical Center, 31 st and Lake Shore Drive, Chicago, IL 60616. Supported in part by NIH Grants HD 11821 and AM 20585.

\section{METHODS}

Animals. Three protocols were followed using ewes and their fetal lambs from 105 to 120 days of gestation, the last trimester of ovine pregnancy, which lasts 150 to 155 days. Supine ewes were anesthetized with halothane, and cesarean section was performed under sterile conditions (11). The distal half of the fetus was delivered from the uterus to the level of the fetal umbilicus. The fetal head remained inside the uterus, submerged in amniotic fluid to prevent fetal respirations. Catheters were sutured into a fetal femoral artery and vein for blood sampling and infusion of drugs and for blood replacement and into a branch of the femoral artery in ewes for blood sampling. An estimate of fetal growth rate during the period of observation was made by measurement of changes in crown-rump length. A 2-0 silk suture was placed in the skin over a lumbar spine with a second suture placed exactly $1.0 \mathrm{~cm}$ apart. At the second cesarean section, the distance between the two sutures was recorded.

Following surgery for each protocol, ewes were allowed to recover and were subsequently routinely fed and allowed free access to water. Ewes were placed in separate cages and blood sampling and intravenous infusions were accomplished without anesthesia or restraint. Fetal and maternal arterial blood was drawn under aseptic conditions in heparinized syringes at surgery and on postoperative days $1,3,5,8$ and 10 , for measurement of $\mathrm{pH}, \mathrm{pCO}_{2}$, and ionized $\mathrm{Ca}^{2+}$. Additional blood was drawn for determination of serum total $\mathrm{Ca}, \mathrm{Pi}, \mathrm{Mg}^{2+}$, and $\mathrm{iPTH}$. Fetal blood was centrifuged at $3000 \times g$ for $5 \mathrm{~min}$ at $4^{\circ} \mathrm{C}$, and the red cells were resuspended in 6 to $8 \mathrm{ml}$ of sterile saline and returned to the fetus via the femoral vein catheter. The serum was again centrifuged at $4^{\circ} \mathrm{C}$ for $15 \mathrm{~min}$ and aliquots were obtained for biochemical measurements. Data are presented only from fetuses in which arterial $\mathrm{pH}, \mathrm{pCO}_{2}$, and $\mathrm{pO}_{2}$ were normal at surgery and remained normal through postoperative day 10 and in which the hematocrit did not change more than $10 \%$ from the initial value at the time of surgery.

Protocols. In protocol 1 (10 animals), fetal kidneys were mobilized from within peritoneal fat through bilateral flank incisions. In four fetuses, bilateral $\mathrm{Nx}$ was performed; in six control animals, "sham" Nx was performed by loosely placing and then removing a ligature from around the renal pelvis. Amniotic fluid losses were replaced with warm saline. The abdominal incision was closed, and fetal catheters were exteriorized via a subcutaneous tunnel to the ewe's upper flank. A catheter was sutured into a superficial branch of the femoral artery in the ewe and exited via a subcutaneous tunnel at the same site as the fetal catheters. Catheters were attached to stopcocks, filled with heparinized saline, and maintained aseptically in a plastic pouch. 
In protocol 2 (three animals), the fetal ureterovesical junctions were identified bilaterally through a suprapubic incision; the fetal ureters were lifted with hemostats and completely severed approximately 0.5 to $1.0 \mathrm{~cm}$ proximal to the ureterovesical junction. The severed proximal ends of the ureters were allowed to retract and drain urine freely into the peritoneal cavity. The peritoneum was closed separately and the suprapubic incision closed in two layers using 3-0 silk sutures. Femoral artery and venous catheters were inserted as described for protocol 1 , and the fetus was returned to the uterus.

In protocol 3 (five animals) bilateral fetal $\mathrm{Nx}$ was performed, and permanent arterial and venous catheters placed as in protocol 1. Approximately $1 \mathrm{~h}$ following surgery, the fetuses were given 0.15 to $0.17 \mu \mathrm{g} 1,25(\mathrm{OH})_{2}$ vitamin $\mathrm{D}$ (kindly supplied by Dr. W. E. Scott, Hoffman La Roche, Nutley, NJ) in $1.0 \mathrm{ml} \mathrm{1,2-}$ propanediol intravenously; this dose was repeated daily for 8 days.

Analytical methods. Blood $\mathrm{pH}, \mathrm{PCO}_{2}$, and $\mathrm{pO}_{2}$ were measured using an Instruments Laboratories blood gas analyzer. Blood ionized calcium was measured with a NOVA II ionized calcium analyzer. Serum total calcium and magnesium were determined by atomic absorption methodology and serum phosphorus by the method of Fiske and Subbarrow (12). Serum iPTH was assayed with bovine antiserum for the carboxyl terminal region of the intact hormone and results are ng equivalents/ml (kindly performed by Dr. Arthur B. Schneider) (13). Statistical analyses for significant differences between mean values were performed using Student's $t$ test. Data are presented as mean \pm SEM. A difference of 0.05 or less was defined as significant.

\section{RESULTS}

Protocol 1. In both experimental and sham-operated fetuses, a small $(1.5$ to $2.0 \mathrm{mg} / \mathrm{dl})$ and insignificant rise in serum phosphorus occurred on days 1 to 2 as a result of surgical trauma. Bilateral fetal Nx, however, caused a rise in serum phosphorus and fall in total serum calcium that was significantly different from simultaneous controls by postoperative day $5(p<0.01 ; p$

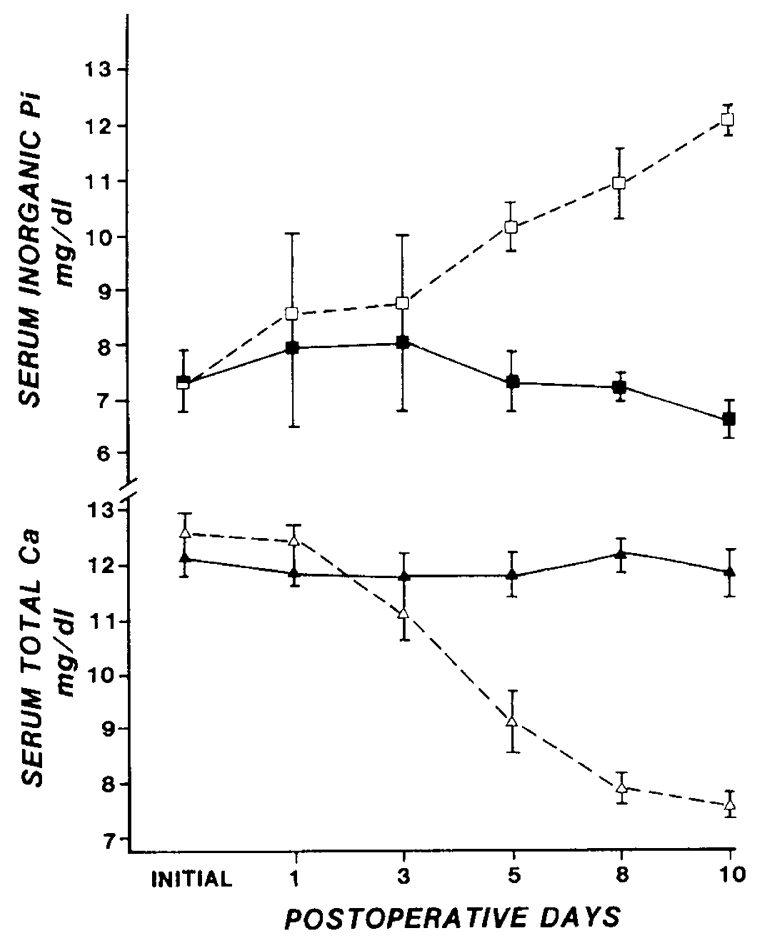

Fig. 1. Serum inorganic Pi (squares) and total calcium (triangles) in control (closed symbols) and nephrectomized (open symbols) fetuses. Controls, $n=6$; nephrectomized, $n=4$.

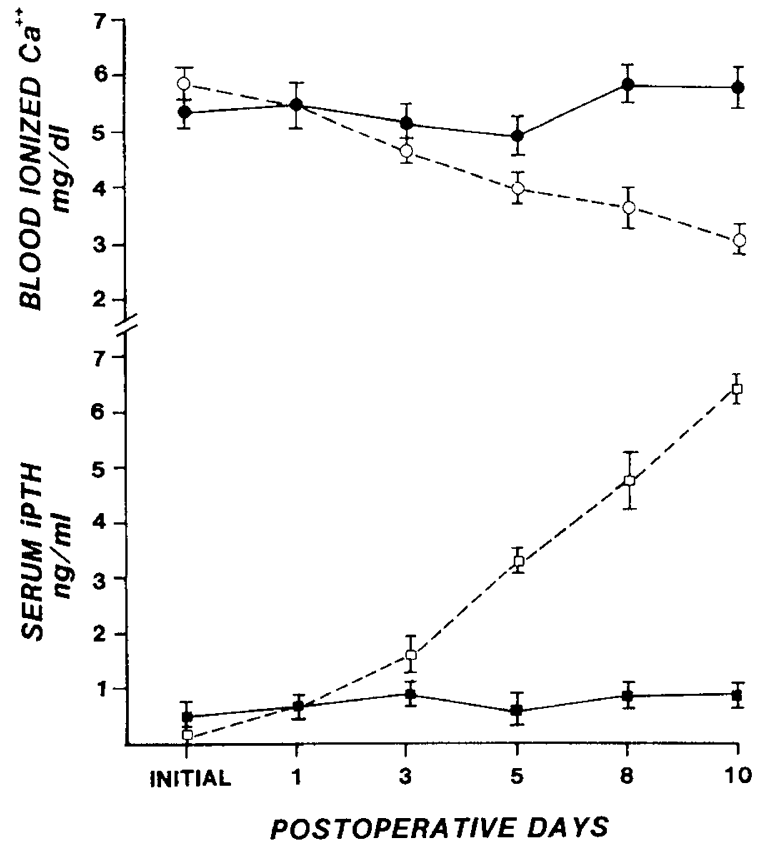

Fig. 2. Blood ionized $\mathrm{Ca}^{++}$(circles) and serum iPTH (squares) in control (closed symbols) and nephrectomized (open symbols) fetuses. Controls $n=6$, nephrectomized, $n=4$.

$<0.001$ ) (Fig. 1). Blood ionized calcium also fell (Fig. 2), and serum iPTH rose; these changes reached statistical significance by postoperative day $3(p<0.001 ; p<0.001)$. In sham-Nx fetuses, serum calcium, ionized calcium, phosphorus, and iPTH values were unchanged by day 10 compared to control values. Values of blood $\mathrm{pH}$ were the same in nephrectomized (7.42 \pm $0.01)$ and sham-operated $(7.39 \pm 0.02)$ fetuses at day 10 and day $1(7.34 \pm 0.07$ versus $7.35 \pm 0.13)$, respectively, as were day 10 $(2.80 \pm 0.15$ versus $3.1 \pm 0.32)$ and day $1(2.76 \pm 12$ versus 2.57 \pm 0.13 ) values of serum magnesium ( $\mathrm{Nx}$ versus sham, in $\mathrm{mg} / \mathrm{dl})$. Maternal values of ionized calcium were normal and therefore less than the control values in all fetuses, and values were not different in sham and $\mathrm{Nx}$ animals. Thus, the ratio of maternalto-fetal ionized calcium rose from the control value of $0.66 \pm$ 0.04 to $1.22 \pm 0.02$ by day 10 in $\mathrm{Nx}$ animals, and remained less than unity $(0.63 \pm 0.04)$ by day 10 in sham- $\mathrm{Nx}$ animals. Tenday crown-rump growth rates were statistically similar $(0.8 \pm$ 0.04 and $0.9 \pm 0.07 \mathrm{~cm}$ ) in experimental and sham fetuses, respectively.

Protocol 2. Bilateral severance of fetal ureters with drainage of fetal urine into the abdominal cavity with peritoneal absorption of fetal urine products produced none of the effects of fetal nephrectomy (Fig. 3). Mean fetal serum phosphorus, total calcium, and blood ionized calcium values were unchanged from control values by day 10 .

Protocol 3. When bilateral fetal $\mathrm{Nx}$ was followed by daily injection of $1,25(\mathrm{OH})_{2} \mathrm{D}_{3}$ beginning immediately after surgery, the rise in fetal serum phosphorus on day 5 did not occur (Fig. 4 ), and serum calcium and blood ionized calcium concentrations remained unchanged. Thus, results in these animals were not different from those in the sham- $\mathrm{Nx}$ (compared to Figs. 1 and 2) and bilateral ureteral severance group.

\section{DISCUSSION}

Bilateral fetal nephrectomy in the 3rd trimester of ovine pregnancy completely disrupted fetal intrauterine calcium and phosphate homeostasis. Fetal serum inorganic phosphate rose significantly and further increased the normal maternal to fetal uphill transplacental phosphate gradient. Fetal total serum calcium and 
blood ionized calcium concentrations decreased significantly, and the normal maternal to fetal uphill transplacental calcium gradient was reversed. These results are not easily explained by generalized placental dysfunction, as all fetuses maintained normal arterial blood gas values, a function solely dependent on normal placental integrity. The excretory function of fetal kidneys also did not seem important, as ureteral transection produced no calcium or phosphorus abnormalities as seen in the adult model (14). This difference is most likely due to the fact that the intact placenta is the major excretory organ in utero and as anticipated, fetal serum urea nitrogen and serum creatinine did not change in either nephrectomized fetuses or in fetuses with ureteral severance (data not shown). However, loss of fetal kidney production of $1,25(\mathrm{OH})_{2} \mathrm{D}_{3}$ seems to have been critical in disruption of fetal mineral homeostasis as daily infusion of $1,25(\mathrm{OH})_{2} \mathrm{D}_{3}$ prevented the abnormalities in nephrectomized fetuses.

The specific pathogenesis of the disruption of fetal mineral homeostasis is not clear. The results suggest that fetal phosphate retention was the primary mineral abnormality and progressive fetal hyperphosphatemia lowered total and ionic calcium concentrations, and low ionic calcium stimulated increased fetal iPTH production. We previously demonstrated that lowering of fetal ionized calcium during short-term EDTA infusion stimulates an increase in fatal serum iPTH activity (15). Although the kidney is the major route for phosphate excretion beyond early life $(16,19)$, it contributes only trivially in utero $(15,18)$ and ureteral severance led to no increase in serum phosphate. Thus, the rise in serum phosphate most likely is the result of retention by the placenta, and we must therefore presume that fetal renal production of $1,25(\mathrm{OH})_{2} \mathrm{D}_{3}$ somehow regulates fetal to maternal phosphate transport via the placenta.

Failing this, the fetal serum phosphate concentration would rise as active maternal to fetal phosphate transport continued, lowering fetal ionized calcium concentration as observed in these studies. There is excellent evidence for bidirectional placental phosphate transport (19-21), but there is no evidence that $1,25(\mathrm{OH})_{2} \mathrm{D}_{3}$ of fetal origin affects placental phosphate transfer. This hypothesis would suggest that active uphill maternal transport of phosphorus to the fetus is not regulated by fetal vitamin D metabolites, whereas unidirectional phosphate transport from

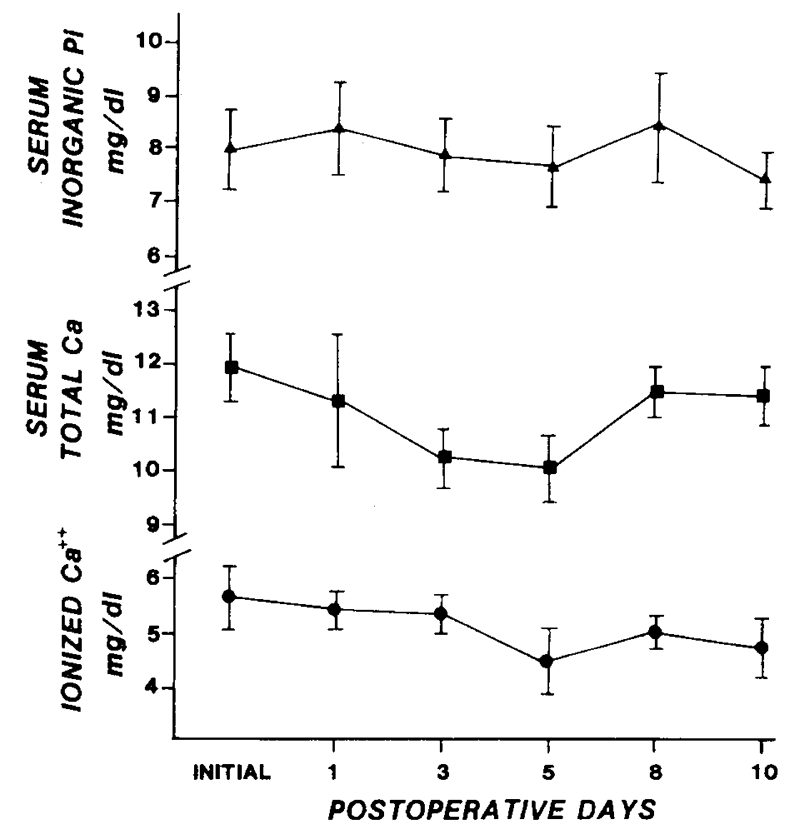

Fig. 3. Serum inorganic Pi (triangles), total Ca (squares), and blood ionized $\mathrm{Ca}^{++}$(circles) in fetuses with ureteral severance and drainage of urine into the fetal peritoneal cavity, $n=3$.

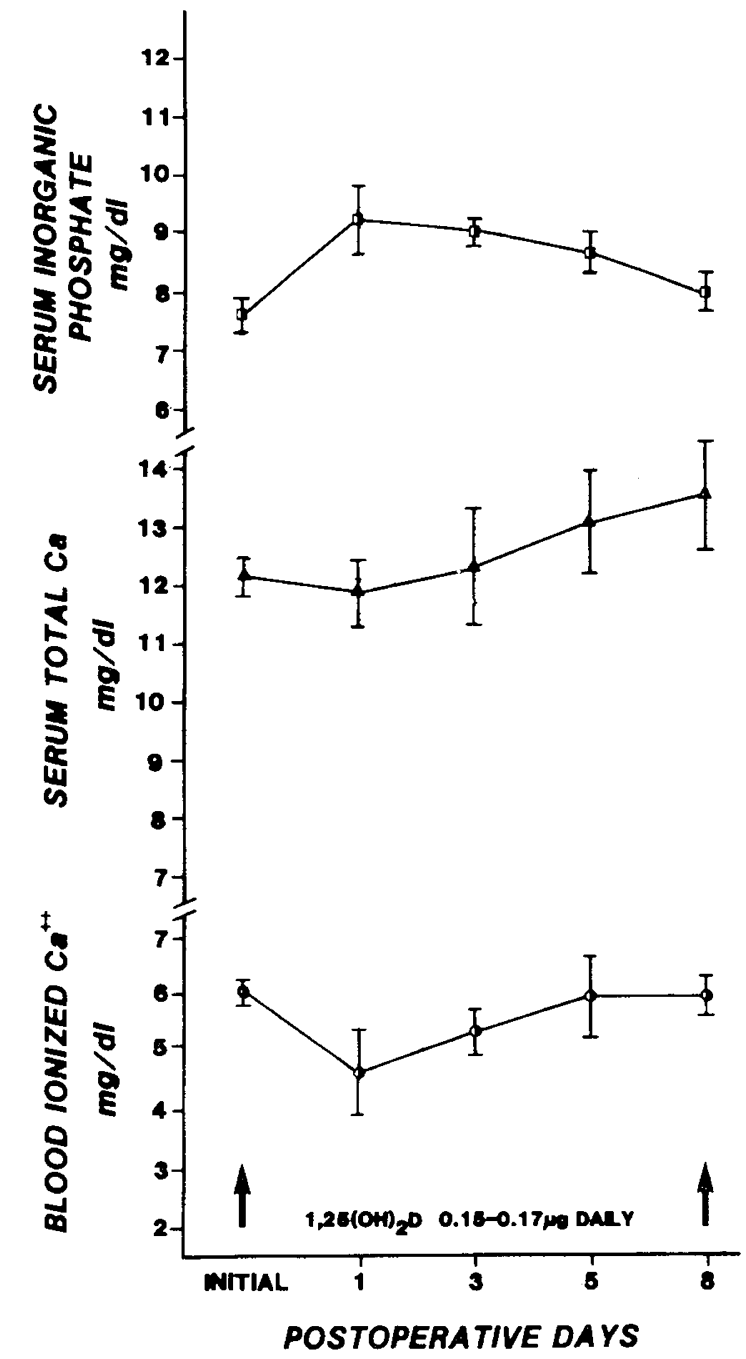

Fig. 4. Serum inorganic phosphate (squares), total serum calcium (triangles), and blood ionized $\mathrm{Ca}^{++}$(circles) in five nephrectomized fetuses receiving $1,25(\mathrm{OH})_{2} \mathrm{D}_{3}$ replacement (half-closed symbols). $1,25(\mathrm{OH})_{2} \mathrm{D}_{3}$ was administered daily beginning immediately after fetal nephrectomy.

fetus to ewe is dependent on fetal kidney $1,25(\mathrm{OH})_{2} \mathrm{D}_{3}$. There is considerable speculation that maternal and/or placenta produced $1,25(\mathrm{OH})_{2} \mathrm{D}_{3}$ stimulates placental divalent mineral transport (22). However, the results in our studies occurred without manipulation of the placenta or the ewe and, therefore, our data do not permit speculation in this regard.

An alternate explanation for the observed results is that fetal renal production of $1,25(\mathrm{OH})_{2} \mathrm{D}_{3}$ is necessary for phosphate accretion into fetal bone, and, failing this, fetal serum phosphate would also rise as active maternal to fetal phosphate transport continued. To date, there are no published studies assessing the effect of fetal produced $1,25(\mathrm{OH})_{2} \mathrm{D}_{3}$ on phosphorus accretion into fetal bone. An additional possibility for the observed results is that fetal produced $1,25(\mathrm{OH})_{2} \mathrm{D}_{3}$ is required for active maternal to fetal uphill calcium transport. This explanation seems unlikely and would leave unexplained the significant rise in fetal serum phosphorus concentration. It is of related interest that $1,25(\mathrm{OH})_{2} \mathrm{D}_{3}$ has been shown to stimulate phosphate transport in the gut (23).

The fall in fetal serum total calcium and in ionic calcium following fetal $\mathrm{Nx}$ in this study is identical to the changes observed after loss of the normal transplacental calcium gradient in nephrectomized fetal sheep fetuses reported by Ross et al. (24, $25)$. However, in that report, fetal blood gas values were not 
reported, so the condition of the placenta after intrauterine surgery could not be determined. Additionally and more importantly in that study, fetal hyperphosphatemia was not described and, therefore, our results appear to be the first to describe fetal hyperphosphatemia after fetal Nx. There are no other published studies of the effect of fetal $\mathrm{Nx}$ on fetal mineral homeostasis.

Acknowledgment. Technical assistance was provided by $\mathrm{M}$. Ocampo and C. Mooers.

\section{REFERENCES}

1. MacDonald NS, Hutchinson DL, Helper M, Flynn E 1972 Movement of calcium in both directions across the primate placenta. Proc Soc Exp Biol Med 119:476 481

2. Pitkin RM 1975 Calcium metabolism in pregnancy: a review. Am J Obstet Gynecol 121:724-736

3. Kelly JJ, Sloan RE, Hoffman W, Sander C 1951 Accumulation of nitrogen and six minerals in the human fetus during gestation. Hum Biol 23:61-66

4. Ziegler EE, O'Donnel AM. Nelson SE, Foman SJ 1974 Body composition in the reference fetus. Anat Rec 179:1-8

5. Boass A, Toverud SU, McCain TA. Pike JW, Haussler MR 1977 Elevated serum levels of 1,25-dihydroxycholecalciferol in lactating rats. Nature 267:630-632

6. Pike JW, Parker JB, Haussler MR, Boass A, Toverud SU 1979 Dynamic changes in circulation 1.25-dihydroxyvitamin D during reproduction in rats. Science 204:1427-1429

7. Gray TK, Lester GE 1979 Evidence for extra-renal $1 \alpha$-hydroxylation of 25 hydroxyvitamin $D_{3}$ in pregnancy. Science 204:1311-1312

8. Tanaka Y, Bottalloran B, Schoes HK, DeLuca HF 1979 In vitro production of 1,25-dihydroxy-vitamin $D_{3}$ by rat by rat placental tissue. Proc Natl Acad Sci USA 76:5033-5035

9. Weisman Y, Harel A, Edelstein S. David M, Spirer Z, Golander A 1979 1,25dihydroxyvitamin $D_{3}$ and 24,25-dihydroxyvitamin $D_{3}$ in vitro synthesis by human decidua and placenta. Nature 281:317-319

10. Fenton E, Britton HT 1980 25-Hydroxycholecalciferol 1-hydroxylase activity in the kidney of fetal, neonatal and adult guinea pig. Biol Neonate 37:254-
256

11. Moore ES, deLannoy CW, Paton JB, Ocampo M 1972 Effect of $\mathrm{Na}_{2} \mathrm{SO}_{4}$ on urinary acidification in the fetal lamb. Am J Physiol 233:167-172

12. Fiske $\mathrm{CH}$, Subbarow YJ 1925 Measurement of inorganic phosphorus. J Etiol Chem 66:375-378

13. Schneider AS, Wells SA, Gunnells J, Leslie JB, Sherwood LM 1977 Regulation of function of transplanted parathyroid glands in man. Am J Med 63:7!10718

14. Nordin BEC, Peacock M 1969 Role of kidney in regulation of plasma calcium. Lancet 2:1280-1282

15. Moore ES, Chung E, Cevallos EE, McMann BJ 1978 Renal phosphate clearance in fetal lambs. Pediatr Res 12:1066-1069

16. Knox FG, Osswald H, Marchand GR, Spielman WS, Haas HA, Berndt T, Youngberg SP 1977 Phosphyate transport along the nephron. Am J Physiol 233:F261-F264

17. Thompson DD, Hiatt $\mathrm{HH} 1957$ Renal reabsorption of phosphate in normal human subjects and in patients with parathyroid disease. J Clin Invest 36:550-554

18. Smith FG Jr, Tinglof BO, Meuli J, Borden M 1969 Fetal response to parathyroid hormone in sheep. Am J Physiol 27:276-280

19. Fuchs F, Fuchs A-R 1956 Studies on the placental transfer of phosphate in the guinea pig: I. The transfer from mother to fetus. Acta Physiol Scand 38:391397

20. Fuchs F, Fuchs A-R 1956 Studies on the placental transfer of phosphate in the guinea pig: II. The transfer from fetus to mother. Acta Physiol Scand 38:391 397

21. Wilde WS, Cowie DB, Flexner LB 1946 Permeability of the placenta by the guinea pig to organic phosphate and its relation to fetal growth. Am J Physiol 147:360-366

22. Bruns ME, Fausto A, Avioli LV 1978 Placental calcium binding protein in rats. J Biol Chem 253:3186-3189

23. Wasserman RH, Taylor AN 1973 Intestinal absorption of phosphate in the chick. J Nutr 103:586-590

24. Ross R, Care AD, Robinson JS, Pickard DW, Weatherley AJ 1980 Perinatal 1,25-dihydroxycholecalciferol in the sheep and its role in the maintenance of the transplacental calcium gradient. J Endocrinol 87:17-18

25. Ross R, Care AD, Taylor CM. Pelc B, Sommerville BA 1979 The transplacental movement of metabolites of vitamin D in the sheep. In: Norman AW (ed) Vitamin D Basic Research and Its Clinical Application. Walter de Gruyter Publishers, Berlin, pp 241-242

\title{
Lung Surfactant Replacement in Premature Lambs with Extracted Lipids from Bovine Lung Lavage: Effects of Dose, Dispersion Technique, and Gestational Age
}

\author{
R. H. NOTTER, E. A. EGAN, M. S. KWONG, B. A. HOLM, AND D. L. SHAPIRO
}

Department of Pediatrics [R.H.N., B.H., D.L.S.], Division of Neonatology, University of Rochester, Rochester, New York 14642 and Departments of Pediatrics [E.A.E., M.S.K.] and Physiology [E.A.E.], State University of New York at Buffalo, Buffalo, New York 14226

\begin{abstract}
Extracted bovine calf lung lipids (CLL) with minimal protein (approximately $1 \%$ ) were instilled prior to ventilation in groups of premature lambs of average gestational ages of 127 and 133 days. Aqueous dispersions of CLL were prepared by two techniques prior to instillation: sonication in an ice bath $(S)$ and mechanical vortexing at room temperature (V). A low surfactant dose (15 mg CLL/
\end{abstract}

Received October 3, 1984; February 12, 1985

Address for correspondence R. H Notter. Department of Pediatrics, Division of Neonatalogy, Box 777, University of Rochester, Rochester, NY 14642.

This study was supported by NIH Grants HL-25170, HL-22522, and HL-00945 (RCDA to RHN) and by Training Grant ES-07026 (to B.A.H.). $\mathrm{kg}$ animal weight) and a high dose $(100 \mathrm{mg} / \mathrm{kg})$ were investigated for each dispersion technique. Following tracheal instillation of surfactant, lambs were ventilated with $100 \%$ oxygen for $2 \mathrm{~h}$ with umbilical circulation intact, and for up to an additional $10 \mathrm{~h}$ after separation. A clear improvement in blood oxygenation and lung compliance was found over controls for lambs given $15 \mathrm{mg} / \mathrm{kg}$ and 100 $\mathrm{mg} / \mathrm{kg} \mathrm{CLL}(\mathrm{V})$, and $100 \mathrm{mg} / \mathrm{kg}$ CLL(S). Lambs treated with $15 \mathrm{mg} / \mathrm{kg}$ CLL(S) failed to improve over controls. Experimental groups treated with equal doses of CLL(V) and CLL(S) had similar amounts of lung lavage phospholipid, with values progressively declining during ventilation. 